\title{
Arbor
}

\section{Teatro público y teatro privado. Opiniones para un debate}

\section{Eduardo Pérez-Rasilla}

Arbor CLXXVII, 699-700 (Marzo-Abril 2004), 525-544 pp.

La cuestión del teatro público y el teatro privado en España ha sido objeto de un acalorado debate desde, al menos, los últimos treinta años y ha producido una casi ingente bibliografía. En ella figuran trabajos muy desiguales, pero merecen rescatarse algunas reflexiones de notable hondura intelectual. A esta bibliografía hemos prestado una especial atención en el presente artículo.

En los años setenta se reclama la intervención de las instituciones públicas en la mejora de un teatro al que se considera comercial y mercantilista. Desde el establecimiento de la democracia, los poderes públicos ponen en marcha algunas iniciativas, sobre todo, el CDN, destinadas a cumplir aquel objetivo. Durante los primeros años del mandato socialista se refuerza la intervención de los poderes públicos sobre el teatro. Sin embargo, las diversas iniciativas han sido fuertemente criticadas desde sus comienzos por razones diversas. Desde mediados de los noventa el modelo parece haber entrado en crisis, sin que por el momento se haya encontrado una solución que resulte aceptable para la mayoría.

Las opiniones sobre el reparto de papeles entre el teatro público y el teatro privado distan de ser concordantes en España. Y no es una discusión nueva. Al menos durante las tres o cuatro últimas décadas el debate ha ocupado páginas de libros y revistas, y tiempos en los foros. Aunque abundan las argumentaciones extemporáneas, los criterios viscerales y 
hasta el insulto a quien se considera un enemigo en esta batalla, es preciso resaltar la altura intelectual que en muchos de los trabajos citados en la bibliografía ha alcanzado el discurso sobre el teatro público y el teatro privado.

El objetivo del artículo que sigue es trazar unas líneas generales sobre la evolución de esta polémica a lo largo de los treinta últimos años, recordar algunos de sus principales hitos y revisar algunos de los numerosos documentos generados por este asunto. Aunque a lo largo de la exposición aparecerán necesariamente algunas cifras, hemos preferido dar prioridad a los argumentos estéticos, políticos o sociales.

\section{La creación del Centro Dramático Nacional}

En los años setenta se van haciendo oír cada vez más voces que denuncian el mercantilismo de la empresa privada dominante y que reclaman, consecuentemente, una mayor presencia de las Instituciones en la actividad teatral. El teatro en España es mayoritariamente comercial y, a juicio de algunos intelectuales y gentes del teatro, radica principalmente en esta circunstancia la causa de la baja calidad media de los espectáculos de la cartelera. Y se solicita un mayor compromiso del Estado con la cultura como fórmula que remedie las carencias y mediocridades que vienen denunciándose desde el comienzo de la posguerra.

Así, por ejemplo, el diagnóstico que proponía Luciano García Lorenzo en las jornadas dedicadas al «Teatro español actual» que se celebraron en la Fundación Juan March en junio de 1976, incidía especialmente en esta cuestión y subrayaba que, a pesar de la exigua iniciativa de los poderes públicos en el teatro, la intervención de éstos había proporcionado los medios para algunas de las más interesantes manifestaciones escénicas del momento:

En España, como en todo el mundo occidental, la primacía, por el número de locales $\mathrm{y}$, en consecuencia, de espectáculos, pertenece a los teatros comerciales, en manos de la empresa privada. Son, naturalmente, los empresarios de estos locales los que manejan en muy gran parte el negocio dramático y esta palabra -negocio- (...) surge de inmediato si de los teatros comerciales hablamos, ya que como tal está considerado por las empresas el arte dramático. (...) Considerando, pues, el teatro como negocio, mandará quien tenga locales y dinero y, por ahora, eso lo tiene personas sin vocación de mecenazgo. (...)

Tampoco el teatro debe estar subordinado a la taquilla, como no lo están los conciertos de una orquesta sinfónica. La obra de teatro, como una novela, un poema, un cuadro o una sinfonía, es arte y el arte no es un negocio; es una necesidad y una necesidad cada vez más imprescindible. La Administración reconoce esto y de ahí la 
Teatro público y teatro privado. Opiniones para un debate

creación de los teatros oficiales: dos en Madrid (Español y María Guerrero) y uno (es en realidad una compañía, La Adrià Gual) en Barcelona. (...) Si frente a la generalidad de los montajes convencionales y la presentación de piezas de claro éxito comercial se crearon los teatros nacionales, también el Ministerio de Información y Turismo ha mantenido durante muchos años el Teatro Nacional de Cámara y Ensayo, que llegó a su más altas cotas a mediados de la década de los sesenta con una serie de estrenos en el Teatro Beatriz de Madrid, de agradable recuerdo para cualquier amante del arte dramático. La controvertida y difícil existencia de este teatro, por otra parte de una necesidad ineludible, pues en él se han realizado las más sistemáticas experiencias del teatro de posguerra, es claro índice de las dificultades con que la vanguardia se encuentra al querer hacerse preguntas ${ }^{1}$.

Sus palabras, pronunciadas en un foro tan significativo entonces y ahora como la Fundación Juan March, expresaban una opinión generalizada que se intensificaría durante los últimos años de la década de los setenta y primeros de los ochenta. Esta manera de pensar tuvo quizás sus primeras consecuencias en la puesta en marcha del Festival de Teatro clásico de Almagro, en 1978, y en la creación del Centro Dramático Nacional, en noviembre del mismo año. Adolfo Suárez era el presidente del gobierno, Pío Cabanillas el ministro de Cultura y Rafael Pérez Sierra el director general. Con esta institución se pretendía ofrecer una versión moderna de los ya política y estéticamente inadecuados Teatros Nacionales, un emblema y un paradigma del teatro público democrático, en suma.

El Teatro María Guerrero pasaba ahora a ser una de las sedes del recién creado Centro Dramático Nacional, pero se consideró insuficiente, y esto es muy sintomático de los nuevos tiempos que corrían, el uso de una sola sala, y se incorporó como segunda sede el Teatro Bellas Artes. La primera estaba destinada en principio a la programación del gran repertorio y la segunda se pensó como ámbito para la experimentación y para el montaje de los textos de los autores españoles contemporáneos. Su primer director será Adolfo Marsillach, a quien las dificultades del empeño le disuadirán muy pronto de continuar la labor. La construcción del edificio teatral público y democrático no iba a ser sencilla. No lo sería nunca. El propio Marsillach ha tenido ocasión de explicar en sus memorias -Tan lejos, tan cerca-, a las que remitimos, las circunstancias en las que se desarrolló su trabajo al frente de su institución y las causas por las que dimitió (2). Entre ellas menciona los desacuerdos con algunos miembros del equipo del CDN, y, sobre todo, la imposibilidad de llevar a cabo una más que razonable aspiración: disponer de unos estatutos que dotasen de autonomía al CDN y lo liberasen de la arbitrariedad política de los gobernantes de turno. Aquel empeño no fue posible entonces ni lo sería después. El CDN dependía del organismo autónomo llamado Teatros Nacio- 
nales y Festivales de España, heredado de la dictadura y que pervivió hasta 1985, ya en la etapa del primer mandato socialista, fecha en la que se creó la estructura del INAEM, sobre el que hoy corren rumores acerca de una profunda transformación.

Además, se producirá un choque entre la cortedad de miras de las autoridades ministeriales y las ambiciosas propuestas del proyecto del director, que incluían, por ejemplo, un seminario para la formación de los actores, a cargo de Miguel Narros, o el establecimiento de un cauce de colaboración con la RESAD, cuyo director era entonces Ricardo Doménech, que formaba parte la nómina de colaboradores del CDN. Nada de esto ha sido posible después.

No omite Marsillach tampoco una cuestión planteada ya en aquellos años y que, no sólo no ha sido resuelta, sino que se ha enconado con el correr del tiempo. Se trata del disgusto de los dramaturgos españoles vivos, que no se han encontrado suficientemente acogidos por las instituciones públicas. Esta actitud se agravó a raíz del despectivo artículo publicado por el crítico Haro Tecglen, entonces miembro de la Junta Técnica, acerca de los dramaturgos españoles, que originó, como era de esperar, la airada respuesta de algunos escritores y críticos y abrió un abismo no cerrado hasta el momento. Ciertamente, en la acalorada discusión, la responsabilidad de Marsillach era muy relativa, pues en la programación de la primera temporada había incluido a tres dramaturgos españoles vivos: Rafael Alberti, José María Rodríguez Méndez y Luis Riaza, de acuerdo con la intención de recuperar la literatura dramática silenciada por el franquismo, objetivo que por entonces parecía a muchos imprescindible a la hora de plantearse las líneas dominantes del teatro en democracia. Sin embargo, la ansiedad originada por un dilatado período de censura y de represión, las expectativas despertadas por la nueva situación política y la incorporación de nuevas generaciones a la escritura dramática generaron unas aspiraciones y también una impaciencia que el teatro español -público y privado- no llegaron entonces -ni mucho menos después- a satisfacer. Y el descontento se canalizó hacia el CDN, actitud que parece haberse repetido recurrentemente hasta nuestros días, y que ha ofrecido uno de los principales veneros de críticas a la institución y al teatro público en su conjunto.

De momento aportó un motivo más a las razones que tenía para no seguir en su cargo el primer director del CDN. Las nuevas autoridades se decidieron por una terna compuesta por Nuria Espert, José Luis Gómez y Ramón Tamayo. En un ponderado artículo escrito en 1988, López Mozo, al hacer balance de los diez primeros años del CDN, sitúa en este período el origen de dos de las actitudes más criticadas a lo largo de la histo- 
ria del CDN. López Mozo censura que algunos de los montajes respondieran a proyectos excesivamente personales o que resultaran innecesaria y desmesuradamente suntuosos:

Interesaba, sobre todo, el teatro hecho, el de calidad, pero para apostar por él hay que gastar mucho dinero. Eso fue lo que hizo el CDN, iniciando un proceso cuyas consecuencias negativas para el resto de la profesión no se hicieron esperar. Los dos botones de muestra fueron Doña Rosita la soltera y Los baños de Argel. La primera dirigida por Lavelli y protagonizada por Nuria Espert, era un canto al divismo. Se trataba de un proyecto de la actriz para su propia compañía, asumido ahora por el CDN y que luego, cuando abandonó el cargo, recuperó para su repertorio. En cuanto a Los baños de Argel, un trabajo teatral de Francisco Nieva sobre la obra de Cervantes, tuvo uno de los presupuestos más altos de toda la historia del teatro español. La complejidad de la puesta en escena fue tal que el teatro María Guerrero hubo de permanecer cerrado durante tres meses ${ }^{3}$.

No faltaron los éxitos de público en aquel período, pero tampoco las críticas, muchas veces agrias, expresadas desde distintos âmbitos. Esta circunstancia y las desavenencias con un nuevo director general condujeron a la sustitución del triunvirato, en 1981, por José Luis Alonso. El Ministerio de Cultura renunció entonces a la segunda sala y el CDN quedaba confinado al Teatro María Guerrero.

Los cambios y las zozobras indicaban, claro es, una cierta inestabilidad de la institución, pero evidenciaban también el empeño por afianzar un proyecto de Teatro Nacional moderno, aunque este objetivo no siempre consiguiera sobrepasar el terreno de las buenas intenciones. Con semejantes propósitos, aunque con desiguales aciertos, se ponen en marcha, durante 1981, el I Festival Internacional de Teatro de Madrid y la normativa para la concesión de ayudas al teatro. El primero tuvo una vida corta, pero brillante, y constituyó el principal puente para la llegada del mejor teatro extranjero a la ciudad y señaló caminos por los que podía discurrir la escena española. El segundo, pese que pretendía aportar una vía de normalización de la vida escénica, fue bastante más discutido.

El 10.I.1981 se publica en el BOE la primera normativa para la concesión de ayudas al teatro. Este suceso, y el debate originado por él, motivaron que el número 187 de Primer acto dedicase un bloque monográfico a la situación del teatro en España, en el que incluía la recién publicada normativa. En aquellas páginas se reconocía la sinceridad del nuevo director general, responsable de la normativa, Juan Antonio García Barquero, y se elogiaban su preparación y su perfil, pero, sobre todo, se ponía el acento en la notoriamente insuficiente cantidad dedicada al Teatro en España y en el, a su juicio, desacertado enfoque ideológico de la política teatral, que, entre otras cosas, no solucionaba el proble- 
ma -detectado ya entonces- de la desconfianza del público español hacia sus dramaturgos contemporáneos, sino que lo empujaba hacia un callejón sin salida. El conjunto de la cantidad con que el Estado español dotaba al Teatro era inferior a la que recibía, por ejemplo, la Comedie française, y suponía la mitad del presupuesto asignado a la Ópera de París.

En un editorial, firmado por la redacción de la revista titulado «Decálogo del vacío» se decía:

Fue terrible por la imagen absoluta de vacío. Por la evidencia de que no existe ninguna política cultural, ni a corto, ni a medio, ni a largo plazo, ni, por tanto, política teatral (...) Fue terrible porque sancionó, por parte de los representantes de la Administración, la defensa de los viejos principios liberales en materia cultural. Según esta argumentación, a mayor intervención del Estado, mayor despotismo; a mayor iniciativa social, menor intervención del Estado, y, por tanto, más democracia. El razonamiento parte de supuestos que quizás correspondan a otros campos de la actividad social, ordenados exclusivamente por el interés económico y la ley de la oferta y la demanda. En el campo de la cultura esto es tan absurdo como en el de la Educación o la Seguridad Social ${ }^{4}$.

Se formulaban así de manera explícita los dos modos de entender la relación del Estado con la Cultura, que proceden de los modelos neoliberales y de los socialdemócratas, respectivamente. La contraposición de estos dos modelos ha continuado hasta nuestros días, pero, mientras las posiciones socialdemócratas parecen haber ido debilitándose progresivamente, los partidarios de las fórmulas ultraliberales se han hecho fuertes desde hace ya algunos años. Sin embargo, no era entonces una opinión en auge. El clamoroso triunfo del partido socialista en 1982 dejará paso, entre otras muchas cosas, a un desarrollo sin precedentes en lo que al teatro público se refiere. El año anterior había contemplado la victoria del Partido Socialista en Francia, y la política cultural y teatral establecida desde el ministerio de Jack Lang y la dirección general de Robert Abirached se va a proponer como modelo para la situación española. En el número 21 de Pipirijaina, publicado en marzo de 1982, Guillermo Heras y Amparo Hurtado ofrecían un trabajo compuesto por un artículo titulado «Francia. Utopía y realidad. Una apuesta por el cambio cultural», una mesa redonda con directores teatrales franceses y entrevistas realizadas a Jack Lang, Robert Abirached, P. Devaux y Bernard Dort. Era evidente que la solución francesa se mostraba como ejemplo del camino que debía seguir la política española. Aunque no faltaba la prudencia, ni tampoco el espíritu crítico y la búsqueda de elementos de contraste, el trabajo dejaba ver la euforia que había invadido los territorios de la creación en Francia y comparaba incisivamente la desproporción existente 


\section{Teatro público y teatro privado. Opiniones para un debate}

entre España y el país vecino en lo que a los medios y las actitudes respecto a la cultura se refiere. Merece la pena recuperar algunos párrafos de aquel trabajo.

Acostumbrados como estamos en España al famoso axioma de las llamadas «tareas prioritarias" sostenidas por los sucesivos gobiernos de UCD y la oposición parlamentaria, no dejará de sorprendernos la rapidez con que el Ministerio de Cultura del vecino país se ha lanzado a un proyecto de transformación del concepto del fenómeno cultural que la derecha llevaba monopolizando durante varias décadas. No es momento, aún, de echar las campanas al vuelo, y por otro lado, no debemos olvidar que estamos delante de un plan marcadamente socialdemócrata, con ribetes progresistas, pero de clara tendencia hacia el modelo germano, en el cual la cultura y, sobre todo, el teatro, está siendo cada vez más absorbido por el Estado. No vamos a dar puntos de vista sobre un tema que requiere todo un debate teórico del que, por desgracia, en nuestro país estamos tan necesitados. (...)

Es muy fácil en un momento como éste hacer apología de las medidas que el Gobierno socialista piensa poner en práctica en los próximos años. Nosotros intentaremos ser objetivos y ofrecer la máxima información real de los planes proyectados, pero aún así no dejan de avergonzarnos las diferencias de criterios y alternativas sostenidas por el equipo de Jack Lang comparadas con las de nuestra señora Soledad Becerril y sus efímeros antecesores en el mismo cargo. Para empezar valga la rotundidad de los presupuestos destinados a la cultura en ambos países. En España 2.000 millones de pesetas, en Francia cerca de 6.000 millones de francos (102.000 millones de pesetas). De aquí emana la cifra de 537 millones de francos (9.129 millones de pesetas) destinados al teatro. No es sólo un problema de dinero, es también una cuestión de concepción. La cultura como instrumento de cambio y como servicio público. "No puede haber cambio de sociedad sin un cambio cultural. La cultura es ante todo una pedagogía de la libertad.», estas cosas suele decir Jack Lang. Aquí, cada vez que un Ministro oye hablar de cultura, saca un televisor o un Mundial de Fútbol, quizá porque la pistola no está bien vista en los últimos tiempos ${ }^{5}$.

\section{El triunfo del PSOE en el 82: el apogeo del Teatro público}

La llegada al poder del PSOE supone para el Teatro la intervención decidida de las instituciones públicas, tal como desde ciertos círculos se había venido reclamando desde tiempo atrás. Se habla incluso de «la hora de la utopía». En 1982, en el número 196 de Primer acto, José Manuel Garrido, recién nombrado director General de Música y Teatro, explicaba de manera sucinta la nueva política teatral. Se mostraba prudente respecto a las cuestiones más polémicas que estaban planteadas, como la Ley del Teatro, y se comprometía a evitar cualquier clase de dirigismo cultural a través de las subvenciones. En el terreno de las promesas hablaba de una tercera sala destinada $a$ otras alternativas teatra$l e s^{6}$, de la creación del Consejo del Teatro y del establecimiento de un circuito de teatros públicos. 
En enero de 1983 la revista Pipirijaina organiza una reunión en la que participan algunos miembros de su consejo de redacción, como Carla Matteini, Ángel García Pintado, Luis Matilla, Guillermo Heras y Moisés Pérez Coterillo, y algunas significadas personalidades del mundo de la cultura y del teatro pertenecientes en aquel tiempo al PSOE, como Salvador Clotas, Fermín Cabal, José Luis Alonso de Santos, Domingo Miras, Alfredo Alonso y Marcial Mateos. La reunión tenía por objeto debatir el documento elaborado por la Comisión de Teatro del PSOE, un ambicioso trabajo que se proponía, entre otros asuntos, la defensa de una cultura nacional, frente a la penetración colonizadora de otras culturas prepotentes $^{7}$. En el ambiente flotaba la necesidad de intervenir en el ámbito de la cultura para impulsar a los creadores propios, objetivo que todos parecían compartir, pero cuya consecución sería muy discutida con el transcurso del tiempo.

La reclamada intervención se haría patente con un extraordinario aumento de los presupuestos. En 1978 el teatro recibe del Estado 325 millones de pesetas. En 1983, recibe 1686 millones y 2393 en 1984. José Manuel Garrido, director general del INAEM primero y subsecretario de Cultura después, es en buena medida el impulsor de este incremento presupuestario y de las iniciativas generadas por la cuantiosa aportación de recursos públicos, pero sus empeños son secundados por algunos sectores de la vida teatral y cultural del país. Sin embargo, esta reivindicación cumplida no estará exenta de problemas. Pronto se levantarán voces contra lo que considerarán un despilfarro de recursos por parte de los teatros públicos, un dirigismo cultural y un arrumbamiento de los teatros privados, que entran por entonces en un proceso de declive. Pero durante la década de los ochenta, e incluso durante los primeros noventa, el modelo implantado por José Manuel Garrido y su equipo funcionará sin excesivos sobresaltos, a pesar de las constantes críticas formuladas desde distintos frentes, y con intenciones y argumentos muy dispares.

Esta nueva etapa lleva consigo la puesta en marcha de iniciativas muy diversas. José Luis Alonso será sustituido al frente del CDN por Lluìs Pasqual, un joven pero ya prestigioso director catalán que procedía del Teatre Lliure. Su nombramiento se producía en el contexto de cambio generacional que iba a afectar a muchos sectores de la vida teatral española y también de la Administración en su conjunto. Al final de la década lo sustituirá, José Carlos Plaza, otro director que procede del Teatro Independiente.

En 1983 entrará en vigor el Estatuto del María Guerrero, sede del Centro Dramático Nacional, que adquirirá la denominación administra- 
tiva de Unidad de producción, perteneciente aún al Organismo autónomo Teatros Nacionales y Festivales de España. En 1984 se pone en marcha el Centro Nacional de Nuevas Tendencias Escénicas, con sede en la Sala Olimpia, con lo que se da cumplimiento a la promesa de ese tercer espacio del que Garrido había hablado al comienzo de su mandato. Guillermo Heras, otro joven profesional que procedía del grupo Tábano, es nombrado director del CNNTE, cargo en el que permanecerá hasta la desaparición del centro. Diez años después, y todavía bajo el mandato socialista, el director general de turno, Juan Francisco Marco, interrumpió bruscamente la trayectoria del centro e incorporó la sala Olimpia al CDN como segundo espacio.

También en 1984, se pone en marcha el Festival de Otoño de Madrid, que, con la colaboración de las tres administraciones, ha continuado hasta nuestros días. En 1985 se constituye, como ya se ha dicho, el INAEM y desaparece, en consecuencia, el antiguo Organismo Autónomo de Teatros Nacionales y Festivales de España. También en 1985 tiene lugar la reunión de Zaragoza, en la que se analiza la situación del teatro público. En 1986, todavía durante la primera legislatura socialista, se formaliza el último gran proyecto público de Garrido: la creación de la Compañía Nacional de Teatro Clásico, cuya dirección se encomendó a Adolfo Marsillach.

Este conjunto de iniciativas, unidas a la intervención de las administraciones municipales y autonómicas en todo el país, con la consiguiente descentralización, cambió sustancialmente el panorama del teatro español. El plan de rehabilitación de teatros, llevado a cabo con el concurso económico del entonces Ministerio de Obras Públicas, recuperó emblemáticos locales en muchas ciudades españolas. Otra cuestión es si la inversión era la más adecuada para la práctica del arte dramático y para la investigación teatral o respondía más bien a criterios de prestigio cultural y a la necesidad de afianzar determinados elementos identitarios de las ciudades. Algunos han criticado, y no les falta razón, que se pretendió la reconstrụcción de espacios del siglo XIX -casi todos los edificios intervenidos eran teatros a la italiana- para la puesta en escena del teatro del siglo XXI. Y, ciertamente, los resultados de tan gran y bien intencionado esfuerzo, no han sido, al menos en el ámbito de lo propiamente teatral, demasiado brillantes.

En cualquier caso, el teatro público pasó a tener un peso y una incidencia en la vida escénica y en la vida social que nunca antes había tenido, lo que permitió que el espectador español pudiera ver con frecuencia espectáculos de una notable calidad formal, gracias a los medios de 
que los teatros públicos fueron dotados. Pero no todos consideraron positivo este fenómeno. Pronto comenzó a hablarse de la competencia desleal de los teatros públicos con los teatros privados, lo que obligaba a éstos a depender de las subvenciones públicas, a subir los precios de las entradas o a abaratar los costes de la producción, con el consiguiente detrimento de la calidad artística. Otros censuraban muchos de los montajes de los teatros públicos, a los que consideraban suntuosos y faraónicos, e inspirados por la prepotencia o por la necesidad de encubrir con un poderoso aparataje una supuesta falta de discurso escénico. Estaban también quienes acusaban a algunos responsables de los teatros públicos de crear espectáculos personalistas o minoritarios, que vaciaban las salas y derrochaban los recursos comunes en aventuras individuales. $\mathrm{Y}$ algunos más, por último, insistían en el carácter inocuo de muchos espectáculos, en su tono complaciente y en el objetivo de no resultar molestos al poder. Muchas de estas críticas se basaron en hechos dignos de ser considerados o en razones de peso; otras, por el contrario, emanaban de envidias, de sentimientos de rechazo o de intereses espurios.

A las críticas generales, se sumaron las críticas específicas respecto a algunas de las instituciones. Son muy conocidas las discrepancias que generaron los montajes de Marsillach al frente de la CNTC, a veces desde criterios puristas o académicos respecto al tratamiento de los clásicos, otras desde el simple desacuerdo con los criterios estéticos e ideológicos del director de la Compañía. El CNNTE suponía una apuesta arriesgada y más aún en una ciudad de gustos dominantemente conservadores, por lo que es comprensible que disgustara a quienes siempre se han mostrado poco amigos de la experimentación y de la novedad. A ellos se unieron quienes se sentían desplazados o preteridos y también los que atentos a las recaudaciones de la taquilla comprobaban que muchos de los espectáculos programados en la sala Olimpia generaban cantidades exiguas, lo que era esperable en un teatro dedicado a la investigación dramática, que proporcionaba un espacio a creadores nuevos y desconocidos en la mayoría de los casos. Y al CDN se le acusó de gastar en demasía y de supeditar en exceso sus programaciones a los gustos personales de sus directores.

Naturalmente hubo quienes valoraron los logros de esta política de apoyo decidido al teatro público. La recuperación del gusto por los clásicos, el descubrimiento de nuevos creadores, la llegada a Madrid de algunos de los grandes espectáculos producidos en Europa, la posibilidad de ver sobre los escenarios en las mejores condiciones los textos de Valle o de Lorca y de otros creadores preteridos por la Dictadura, la indiscutible mejora de calidad en lo que a las escenificaciones se refiere o la dignifi- 


\section{Teatro público y teatro privado. Opiniones para un debate}

cación del teatro en su conjunto son algunos de los aspectos que merecen ser resaltados y que responden a un momento económico, político y social concreto y también al impulso creador y vital de una sociedad que emergía, por fin, de un largo período de represión y letargo.

No obstante, el tono negativo de las opiniones adversas fue cambiando el clima respecto al teatro público, que, en gran medida concitó las iras de muchos y hubo de cargar con los problemas del teatro español, de los que no siempre era responsable. Y así parece haberse perpetuado la imagen de un teatro público lujoso, evasionista y anquilosado, desconectado del público y de la realidad circundante. En 1997 Alberto Miralles ofrecía una visión retrospectiva, documentada y aguda, y en ella incidía en la idea de un teatro público como un ámbito poco o nada conflictivo, dotado de un prestigio cultural ajeno a la contemporaneidad, porque se ha empeñado en mirar hacia el pasado. Sus conclusiones están impregnadas de sarcasmo:

¡Los clásicos! Esa era la solución. Está comúnmente aceptado que los clásicos elevan el espíritu, que suponen el mantenimiento de nuestro magnífico pasado y que su literatura es, aunque algo abstrusa, potente. Pero la mayor de sus ventajas (...) es que los conflictos que plantean, por mucho que se los quiera comparar con los actuales, no dejan de ser de hace cuatrocientos años y escritos en verso, lo cual hace que su hipotética actualidad esté diluida y, en el caso de que sean comprendidos, absolutamente asimilables. Todo eso conduce a la mayor ventaja de todas: la inanidad de su mensaje crítico. (...) como estrategia estatal, la necrosis artística se iba a extender durante el gobierno de UCD y, ya en plena democracia, con el Partido Socialista, que perfeccionó y aumentó la necrofilia. (...) A partir de 1981, se inició en la España teatral un tufillo a necrológica que privó a la escena del dinamismo necesario. Mal apoyo era ése para quienes luchaban contra el desencanto ${ }^{8}$.

\section{La crisis de un modelo}

Hacia 1990 parece tomarse conciencia por primera vez de la posible crisis del modelo. El número 78 de El público incluye un bloque monográfico precisamente con ese título. Entre los textos que se recogen aparece un editorial firmado por el director, Moisés Pérez Coterillo, y un ponderado, agudo y preciso trabajo de Alberto Fernández Torres, titulado La crisis de identidad en el teatro público en España. En él advierte sobre ciertos problemas que se están detectando en diferentes ámbitos y modelos de algunos teatros públicos europeos, como el francés, el belga o el inglés, y parangona su situación con la española. Desde una actitud crítica, aunque no alarmista, Fernández Torres invita a mirar a aquellas situaciones del teatro europeo, pero no sin hacer constar, por un lado, las 
enormes diferencias presupuestarias y de infraestructuras entre los países a los que se refiere y el nuestro y, por otro, la circunstancia de que los principales problemas del teatro público español proceden del origen del $\mathrm{CDN}$, sobre cuya constitución faltó un verdadero debate y careció de un paradigma claro:

(...) la creación del CDN por parte de la UCD no respondió realmente a la voluntad de traducir al castellano modelo europeo de teatro público alguno, sino de contar con una fábrica de éxitos teatrales "ad majorem Dei gloriam".

Se sabía, eso sí, que Europa adelante había teatros nacionales. Pero en ningún caso se pensaba que el CDN fuera a cumplir la histórica función de éstos ${ }^{9}$.

El prudente análisis concluye con un epígrafe titulado «Recapitulaciones», en el que sale al paso de posibles interpretaciones interesadas y precipitadas:

No se pretende con lo dicho efectuar un juicio apocalíptico sobre la situación del teatro público en España. Ni cuestionar su necesidad. Ni menospreciar su papel en la revitalización del panorama teatral que ha tenido lugar en los últimos años. Pero sí llamar la atención sobre una doble realidad: en primer lugar que su incierto arranque, la indefinición o mala definición inicial de sus objetivos, su pobreza presupuestaria en comparación con otras entidades públicas europeas, su funcionamiento descoordinado, su inadecuado régimen jurídico y económico, y su excesiva dependencia respecto de los vaivenes de la política hacen de estos centros unas entidades particularmente vulnerables. (...)

En segundo lugar, los teatros públicos se están viendo afectados en la mayor parte de los países europeos por situaciones críticas de muy diverso tipo. Las diferencias entre unos y otros son evidentes. Pero no parece lógico pensar que esos problemas no nos afectan ya de una $u$ otra forma. O que no nos vayan a afectar en un mañana no muy lejano. No se trata de hacer tabla rasa de lo existente y partir otra vez de cero. Pero sí de pensar que el teatro público en España es aún lo suficientemente joven como para poder asumir sin traumas, procesos de reconversión, reforma o modificación -sean totales o parciales- que no sólo reduzcan su vulnerabilidad, sino que permitan además prever las crisis por las que están pasando otras entidades europeas y conseguir una adecuación completa -y no espontánea o intuitiva- del teatro como servicio público a la realidad española ${ }^{10}$.

En suma, el trabajo de Fernández Torres animaba a reforzar las estructuras de nuestro teatro público, a la vista de las crisis de otros modelos y de la debilidad del nuestro. Pero sus consejos, previos a la reunión sobre los teatros públicos que había de celebrarse en Valencia en aquel mismo año, fueron desoídos y, a mediados de los noventa, esa debilidad se acentúa, justamente cuando arrecian las críticas de los enemigos políticos y estéticos -dejemos de lado a los revanchistas, que los hubo, y muchos- del modelo.

En 1994 aparece el libro de Fermín Cabal titulado La situación del teatro en España. Cabal, dramaturgo y antiguo militante del PSOE y muy 


\section{Teatro público y teatro privado. Opiniones para un debate}

crítico después con la actuación teatral y política del que había sido su partido, venía ya investigando y publicando desde hacía algún tiempo acerca de los problemas políticos y económicos del teatro. El libro llama la atención sobre la pérdida.creciente de espectadores y combina un cierto alarmismo, sobre todo respecto a la previsible desaparición del teatro privado, con un considerable acopio de información -a veces un tanto ecléctica y recogida de otras fuentes, como por ejemplo el trabajo de Fernández Torres anteriormente citado- y, también con un deseo de ecuanimidad y equilibrio, que le lleva reconocer determinados logros. Pero el conjunto de su trabajo cuestiona radicalmente el modelo vigente desde un punto de vista económico e ideológico, después de analizar los resultados del programa teatral del Ministerio de Cultura, lo que le lleva a preguntarse:

¿Quiere decir esto que el teatro público es un lastre que hay que tirar a la basura? Hoy día son muchas las voces que se alzan entre la profesión en demanda de medidas drásticas. Quienes consideran, desde una perspectiva neoliberal hoy de moda, que la intervención del Estado es intrínsecamente perversa, hablan de privatizar los teatros públicos, suprimir el Ministerio de Cultura, acabar con la política de subvenciones, etc. En parte hay que interpretar el predicamento que adquieren últimamente como síntoma del profundo malestar que ha originado una política destructiva del tejido teatral. En parte, también, son voces interesadas en volver a una situación anterior (y coloreada en rosa por la nostalgia) en la que un cierto tipo de teatro, el teatro comercial tradicional, se desenvolvía como pez en el agua. Pero las exigencias de una sociedad postindustrial son mucho más complejas ${ }^{11}$.

$\mathrm{Y}$, sin dar todavía una respuesta definitiva, considera que un importante factor de legitimación ideológica fue la teorización del teatro como servicio público, que había sido ampliamente difundida en la Europa de posguerra ${ }^{12}$, pero entiende que ese modelo no era válido en un contexto histórico distinto, y que, por otra parte, había entrado en crisis ya desde la década de los sesenta. A pesar de lo cual y de las críticas vertidas sobre el modelo, que recoge y clasifica, concluye que los teatros públicos pueden y deben cumplir un papel muy importante en la estructura teatral española: el de correctores del mercado cuando los intereses estratégicos de la cultura no puedan ser satisfechos por la iniciativa privada ${ }^{13}$. Es decir, frente a la idea del teatro como servicio público, la prioridad de la iniciativa privada, y la relegación de los poderes públicos a la función meramente subsidiaria.

También Moisés Pérez Coterillo venía publicando artículos en el diario El Mundo en los que hacía hincapié sobre la pérdida creciente de espectadores y sobre el retroceso del teatro privado. La exposición de estas ideas, junto la sistematización de los datos estudiados, aparecería en 
el volumen titulado Los teatros de Madrid 1982-1994, publicado por FAES.

Casi al mismo tiempo y publicado por la misma editorial, aparecía el libro programático de Eduardo Galán, con la colaboración de Juan Carlos Pérez de la Fuente y con prólogo de José María Aznar, titulado Reflexiones en torno a una política teatral. Como es bien sabido, el triunfo del Partido Popular en las elecciones de 1996 llevaron al prologuista a la presidencia del gobierno, al autor a la subdirección general de Teatro y al colaborador a la dirección del CDN. A pesar de que la redacción evidenciaba curiosos equilibrios que permitieran mantener un tono moderado y no molestar a algunos creadores y responsables de iniciativas teatrales anteriores, o no causar excesiva alarma, el discurso se presentaba como una crítica feroz a la gestión socialista del teatro durante la época de su mandato. La actitud de los autores puede comprenderse por el enrarecido clima político que caracterizaba a un período en el que se presentía un inminente cambio de gobierno. Así, no es extraño un tono catastrofista que incide en que el público ha abandonado los teatros o en que a menudo se han representado espectáculos de difícil comprensión y valoración artísti$c a^{14}$, o que el teatro ha dejado de ser un fenómeno popular y se ha convertido en un acontecimiento elitista y un espectáculo minoritario ${ }^{15}$ y se llega a conclusiones restallantes cuyo lenguaje adquiere en ocasiones resabios de libelo. Así, por ejemplo:

De ahí que no pueda negarse que nos hallamos ante un teatro fundamentalmente intervenido, por el poder político, que ejerce un férreo control presupuestario y cuyas consecuencias más graves se resumen en la pérdida de una parcela significativa de la libertad de creación y expresión ${ }^{16}$.

O también: No resulta admisible mantener por más tiempo la cultura del fracaso subvencionado ${ }^{17}$, lo cual lleva, lógicamente a la conclusión de que efectivamente, se debe primar el éxito. Aunque implique que los que más recaudan por taquilla más ayuda reciban del Estado ${ }^{18}$.

Y los equilibrios vuelven a la hora de referirse a los teatros públicos. Tras criticar acerbamente la trayectoria de estas instituciones durante la etapa socialista, se titubea a la hora de proponer una solución drástica que parecería desprenderse de algunos de los análisis y argumentos expuestos:

Consideramos que es imprescindible un análisis detallado y riguroso de los presupuestos y funcionamiento de todos los teatros públicos en España para que una nueva política teatral pueda resultar efectiva. En principio, resultan convincentes las razones que se esgrimen para defender la existencias de un Centro Dramático Nacional, una compañía Nacional de Teatro Clásico. Deben cuestionarse la existencia (sic) de algunos teatros de titularidad pública (...) Ahora bien, en estos momentos 


\section{Teatro público y teatro privado. Opiniones para un debate}

consideramos desaconsejable el desmantelamiento generalizado de los teatros públicos y la privatización de su gestión. Antes sería imprescindible el saneamiento de la empresa privada. Conviene, creemos, disminuir el número de producciones propias y avanzar en el terreno de la coproducciones con las empresas privadas ${ }^{19}$.

Un poco antes de la publicación de estos tres libros mencionados, Juan Antonio Hormigón salía al paso del previsible ataque contra los teatros públicos en un breve, pero exacto y contundente artículo con el que abría el bloque monográfico que el número 31-2 de la revista $A D E-T e a-$ tro dedicaba a la cuestión. En él explicaba la razón de ser y la historia de los teatros públicos $\mathrm{y}$, tras asumir las críticas que pesaban en aquellos momentos sobre los teatros públicos, apostillaba:

Los vicios inherentes a los procesos, la satrapía de ciertos directores que consideran las instituciones que dirigen como su propiedad privada, la mala gestión, la ausencia de responsabilidad, las carencias programáticas, los repertorios desequilibrados o inconsecuentes, el ineficaz trabajo con el público y tantas otras cosas, son hechos negativos que deben analizarse, luchar contra ellos y corregirse. Nada de ello, en tanto que constituyen hechos ocasionales, puede cuestionar los principios en los que se sustenta la existencia del Teatro Público ${ }^{20}$.

Pese a todo lo dicho anteriormente, cuando el PP llega al poder, mantuvo básicamente las mismas estructuras teatrales que se encontró, y, curiosamente, un cambio que se preveía traumático se convirtió en una continuidad tranquila, aunque, a lo largo de estos ocho años, los problemas con las salas se fueron sucediendo. Primero fue preciso cerrar la Olimpia, para iniciar la construcción de un teatro, cuyas obras parecen avanzar a buen ritmo y ofrecen, por fin, buenas perspectivas. Después, se procedió a la adquisición del Teatro de la Comedia, sede de la CNTC, hasta entonces utilizado en régimen de alquiler, pero su compra ha ido seguida del cierre para las necesarias reformas y el traslado de la Compañía al Teatro Pavón. Por último, el María Guerrero tuvo que cerrarse a la vista de los problemas que amenazaban con la ruina del edificio hasta que finalmente, en 2003, pudo reabrirse al público. Lo perentorio ha prevalecido sobre lo ideológico.

El teatro privado, salvo honrosas excepciones, parece haberse encastillado desde hace algunos años en las programaciones más rancias y anacrónicas, desmintiendo a quienes confiaban en él como solución a los problemas del teatro madrileño. Los musicales parecen haber animado la taquilla, pero, desde luego, no han satisfecho tampoco las inquietudes de quienes esperan un teatro progresista de calidad.

El nuevo cambio político abre una nueva etapa y se enfrenta a una situación un tanto apática e incluso inane. Es preciso no aplazar ya más un conjunto de reformas que vienen haciéndose necesarias desde hace 
mucho tiempo y que han de fortalecer al endeble edificio de los teatros públicos españoles. Como en otras esferas de la vida pública, es mucho lo que el teatro espera de la nueva Administración.

\section{Notas}

1 García Lorenzo, Luciano: en AAVV: Teatro español actual, Madrid, Cátedra-Fundación Juan March, 1977, págs 24-26.

${ }^{2}$ Marsillach, Adolfo: Tan lejos, tan cerca, Barcelona, Tusquets, 1998, págs. 391-404.

3 López Mozo, Jerónimo: "Avatares del teatro español», en Reseña n.184, 1988, págs. 4-5.

4 “Decálogo del vacío», en Primer acto, n 187, pág. 4.

5 Heras, Guillermo y Hurtado, Amparo: «Francia. Utopía y realidad. Una puesta por el cambio cultural», en Pipirijaina, n. 21, marzo 1982, pág. 44.

6 Garrido, José Manuel: “Las líneas de una política teatral», en Primer acto n. 196, noviembre y diciembre de 1992 , pág. 3

7 AAVV: "Mesa redonda con la comisión de teatro del PSOE", en Pipirijaina, n. 24, enero 1983, pág. 22.

8 «La memoria asesinada», en AAVV: Creación escénica y sociedad española (Mariano de Paco, ed.), Universidad de Murcia, 1998, pág. 115.

9 Fernández Torres, Alberto: «La crisis de identidad del teatro público en España", en $E l$ público, n. 78, mayo-junio 1990, pág. 65.

10 Op.cit., pág. 68.

11 Cabal, Fermín: La situación del Teatro en España, Madrid, AAT, 1994, pág. 41.

12 Op.cit., pág. 42

13 Op.cit., pág. 44

14 Galán, Eduardo y Pérez de la Fuente, Juan Carlos: Reflexiones en torno a una política teatral, Madrid, FAES, (s.a., en torno a 1995), pág. 17

15 Op.cit., pág. 21.

16 Op.cit., pág. 16.

17 Op.cit., pág. 19

18 Op.cit., pág. 105 (Las negritas son de los autores)

19 Op.cit., págs. 84-5.

20 Hormigón, Juan Antonio: «Pasado y presente del teatro público», en ADE-Teatro n. 31-2, septiembre 1993, pág. 5

\section{Bibliografía}

AAVV (1988) : «Andalucía. El Centro de Teatro Sociedad Anónima», en El público, n. 5859, julio-agosto, págs. 94-96.

AAVV (1989): “Andalucía El año en el que el CAT echó a andar«, en, El público, n.70-71, julio-agosto, págs. 88-90.

AAVV (1996): “Cambios en los Teatros Nacionales«, en Primer acto n. 264, julio-agosto, págs. 96-103. 


\section{Teatro público y teatro privado. Opiniones para un debate}

AAVV (1998): Creación escénica y sociedad española (Mariano de Paco, ed.), Universidad de Murcia.

AAVV (1998): Centro Dramático Nacional. XX años, Madrid, INAEM, .

AAVV: «Debate sobre teatro y autonomías«, Separata de Primer acto n. 223, marzo-mayo 1988.

AAVV (1988): «Debate sobre locales teatrales«, Separata de Primer acto, n. 224, junio-julio.

AAVV (1985): El mapa teatral de España, Cuadernos El público n. 2, febrero.

AAVV (1986): «El teatro de las autonomías a marchas forzadas«, en $E l$ público, n. 34-5, julio-agosto, págs. 93-108.

AAVV (2002): El teatro español ante el siglo XXI (Oliva, César, ed.), Madrid, Sociedad Estatal Nuevo Milenio.

AAVV (2001): «El Teatre Lliure, abierto. (Manifiesto)», en ADE-Teatro, n. 86, julio-septiembre, pág. 11.

AAVV (1983): Estatuto del Teatro María Guerrero, en El Público, n. 0, Verano, pág. 4.

AAVV (1996): «Estructura y organización teatral «, en ADE-Teatro, n. 50-51, abril-junio, págs. 14-78.

AAVV (1995): Historia de los teatro nacionales, vol II, (Andrés Peláez, ed.), Madrid, Centro de Documentación Teatral.

AAVV (1993): «INAEM, nuevas órdenes ministeriales«, en Primer acto n. 247, enero-febrero, págs. 43-49.

AAVV (1999): Los Teatros de Madrid 1994-1998, Madrid, Centro de Documentación Teatral.

AAVV (1983): «Mesa redonda con la comisión de teatro del PSOE», en Pipirijaina, n.24, enero, págs. 22-29.

AAVV (2002): "Modelos de organización teatral" y "Difusión y distribución del teatro en España«, en ADE-Teatro n.89, enero-marzo, págs. 68-114 y 133-160.

AAVV (1992): Política teatral. Separata de Primer acto n. 242, enero-febrero.

AAVV (1981): «Política y teatro«, en Primer acto n. 187, diciembre 1980-enero 1981, págs. $2-16$.

AAVV (1993): «Por el interés público del arte y la cultura. Manifiesto«, en Primer acto n. 249, mayo-junio, pág. 9.

AAVV (1989): «Teatro«, en Doce años de cultura española, Madrid, Encuentro.

AAVV (1977): Teatro español actual, Madrid, Fundación Juan March-Cátedra.

AAVV (1993): Teatros públicos, en $A D E$-Teatro n.31-32, septiembre. Número monográfico.

AAVV (1969): Teatros y politica, Buenos Aires, Ediciones de la Flor.

AAVV (2001): "Un plan Nacional para el Teatro", en ADE-Teatro, n. 84, enero-marzo, págs. 5-9.

ABIRACHED, RoBert (1992): El teatro y el príncipe. 1981-1991, París, Plon.

- (2003): “El teatro, servicio público: los avatares de una moción«, en ADE-Teatro, n. 95, abril-junio, págs. 51-54.

AGUILAR, MANU (1989): «Gestión de teatros públicos«, en Primer acto n. 229, enero-marzo, págs. 88-89.

BENACH, JOAN-ANTON (1983): «Teatro y administración local. Un pacto imprescindible», en El público, n. 2, noviembre, págs. 3-5.

CABAL, FERMín (1994): La situación del teatro en España, Madrid, AAT.

- (1992): «Los males del teatro en Madrid», en ABC. 20.XI.1992, pág. 3. 
- (1993): «Los males del teatro nacional «, en $A B C .14 . V .1993$, pág. 3.

Cabal, Fermín y Alonso de Santos, José Luis (1985): Teatro español de los 80, Madrid, Fundamentos.

CABAllero, ERnesto (2002): “Lo que pasa», en Las puertas del drama, número 8, invierno, págs. 24-5.

CAMPOS, Jesús (2003): “Comparecencia en el Senado», en Las puertas del drama, n. 16, otoño, págs. 10-13.

CaÑizares Bundorf, Nathalie (2000): Memoria de un escenario. Teatro María Guerrero. 1885-2000, Madrid, Centro de Documentación Teatral.

Cimarro, Jesús (1997): Producción, gestión y distribución del teatro, Madrid, SGAE,

D.C. (1984): Así se emplean los dineros del teatro, El público n. 5, febrero, págs. 11-13.

Díaz Sande, José Ramón (1988): “El teatro no es sólo Madrid“, en Reseña, n. 184, mayo, págs. 16-20.

FERNÁNDEZ LERA, ANTONio (1984): "Comparaciones odiosas. Los dineros del teatro francés«, en $E l$ público, n. 13, octubre, págs. 16-17.

Fernández Torres, Alberto (1993): “¿Ausencia de política o política de ausencia?», en ADE-Teatro, $\mathrm{n}^{\circ} 33$, diciembre, págs. 77-79.

- (1998): «Datos sobre el mercado teatral madrileño. Vamos mejor (aunque no sabemos a dónde)", en $A D E$-Teatro,'n. 68-69, julio-septiembre, págs. 188-193

- (1997): «EEl final de algo viejo o el principio de algo nuevo? Un análisis básico de la encuesta de la Red Española de Teatros y auditorios «, en ADE-Teatro, n. 60-61, julioseptiembre, págs. 112-123.

- (1996): "Las subvenciones al teatro: Sobre el chocolate del loro y otros temas recurrentes», en ADE-Teatro, n. 52-53, julio-septiembre, págs. 29-34.

- (2000): "Los autores españoles vivos en las producciones del CDN. Una cuestión de coherencia", en Las puertas del drama, n. 1, invierno, pág. 36.

Galán, Eduardo y PÉRez de la Fuente, JuAn CARLOS (s.a.): Reflexiones en torno a una politica teatral, Madrid, FAES.

García LoREnZo, LUCiano (1981): Documentos sobre el teatro español contemporáneo, Madrid, SGEL.

GARRIDO, JosÉ MANUEL (1989): “Balance de gestión teatral (1982-88)», en ADE-Teatro n ${ }^{o}$ 10, págs. 6-8.

- (1984): “España en el teatro de Europa», en El público n. 5, febrero, págs. 2-3.

- (1982): «Las líneas de una política teatral», en Primer acto n. 196, noviembre-diciembre, págs. 2-3.

- (1984): «Sociedad democrática y teatro«, en Primer acto n. 207, enero-febrero, págs. 13-17.

Heras, Guillermo (1994): Escritos dispersos, Madrid, CNNTE,

- (2003): Miradas a la escena de fin de siglo (Escritos dispersos II), Valencia, Universidad, .

- (1993): «Un servicio público y social«, en $A D E$-Teatro, n. 31-32, septiembre, págs. 8790.

Heras, Guillermo y Hurtado, Amparo (1982): “Francia», en Pipirijaina, n. 21, marzo, págs. (46-65).

HORMIGÓN, JUAN ANTONIO (1984): «Luces y sombras del presente teatral», en El público, n. 6, marzo, págs. 3-5.

- "Pasado y presente del Teatro Público“ (1993), en ADE-Teatro, n. 31-32, septiembre, págs. 4-5. 


\section{Teatro público y teatro privado. Opiniones para un debate}

- (2003): «Proyecto de un Plan Nacional de Teatro«, en ADE-Teatro, n. 95. Abril-junio, págs. 55-61.

- (1974): Teatro, realismo y cultura de masas, Madrid, Edicusa.

LANG, JACK (1968): L'etat et le Théatre, París, LGDJ.

LISSAVETZKY, JAIME (1995): “Un proyecto socialista para la cultura en Madrid, en ADETeatro, n. 43-44, abril, págs. 106-108.

LÓPEZ ANTUÑANO, JoSÉ GABRIEL (1997): «Algunas propuestas para los teatros públicos de provincias", en $A D E$-Teatro, n. 56-57, enero-marzo, págs. 61-63.

LÓPEZ Mozo, JERónimo (1988): "Avatares del teatro español», en Reseña, n.184, mayo, págs. 4-7.

MARSILlaCH, AdOLFO (1999): «¿Quién dirige un teatro nacional?», en ADE-Teatro, n 78, diciembre, págs. 10-11.

- (1998): Tan lejos, tan cerca, Barcelona, Tusquets.

MATABOSCH, JoAN (1988): “Dos lustros de teatro en Cataluña“, en Reseña, 184, mayo, págs. 10-15.

Medina Vicario, Miguel (1976): El teatro español en el banquillo, Valencia, Fernando Torres editor.

Miras, Domingo y Marsillach, Adolfo (1996): «10 años de la Compañía Nacional de Teatro Clásico", en Primer acto n. 262, enero-febrero, págs. 105-110.

Monlé́n, José (1995): «A vueltas con el Centro Dramático Nacional«, en Primer acto 260, septiembre-octubre, págs. 3-6.

- (1981): "Sobre la ausencia de una política teatral", en Primer acto n. 190-191, noviembre-diciembre, págs. 6-14.

- (1993): «Sobre lo público y lo privado, el debate electoral, la respuesta de los artistas y el cierre del Teatro Madrid", en Primer acto n. 249, mayo-junio, págs. 4-8.

OlIVA, CÉSAR (2002): Teatro español del siglo XX, Madrid, Síntesis.

PÉrez Coterillo, Moisés (s.a.): Los teatros de Madrid. 1982-1994, Madrid, FAES.

PÉrez Coterillo, Moisés, Fernández Torres Alberto et al. (1990): “Teatros públicos: la crisis de un modelo«. (Monográfico sobre el teatro público), en El público, n. 78, mayo-junio, pág. 1 .

PÉREZ-RASILlA, EdUARDO (1996): “El teatro español durante los últimos doce años. Notas para un análisis", en $A D E$-Teatro n. 50-51, abril-junio.

PUJOL, JORDI (1997): «Extractos del discurso para el acto de inauguración del Teatro Nacional de Cataluña", en ADE-Teatro, n 62-63, octubre-diciembre, págs. 42-43.

PuYó, CARMEN (1985): "Primera piedra del Centro Dramático de Aragón“, en El público, n. 19, abril, pág. 48.

ROdRíguez, CARLOS (1992): «El teatro y las instituciones. Entrevista a Juan Francisco Marco", en ADE-Teatro, n. 27, noviembre, págs. 7-10.

RodríGuez Méndez, José MARÍA (1993): Los despojos del teatro, Madrid, Julia García Verdugo ed.

Ronfani, Ugo (1987): Yo, Strehler. Conversaciones con Ugo Ronfani, Barcelona, ediciones Ultramar (con prólogo de Lluìs Pasqual)

SAdOWSKA GuILLON, IRÈNE (1996): “Medios financieros y prioridades. El teatro, un servicio público“, en ADE-Teatro, n. 52-53, julio-septiembre, págs. 35-41.

Trancón, SANTiAgo (1993): “Red nacional de Teatros públicos«, en Primer acto n. 247, enero-febrero, págs. 36-42.

Vicente Mosquete, José L. (1987): «Los teatros públicos. ¿La Meca del actor?», en El público, n. 40, enero, págs. 26-35. 


\section{Eduardo Pérez-Rasilla}

544

- (1985): "Teatro público: de una conferencia hacia un circuito», en El público n.21, julio, págs. 13-18.

VIEITES, MANUEL F. (2004): “iNo nos defraude, por favor!», ADE-Teatro n. 100, abril-junio, págs. 9-11.

- (2003): «Una política teatral en democracia», en $A D E$-Teatro, n. 95, abril-junio, págs. 35-50.

VILAR, JEAN (1975): El teatro, servicio público, y otros textos, París, Gallimard. 